\title{
Obstáculos para retorno ao trabalho: tradução e adaptação cultural do questionário para o contexto brasileiro
}

\author{
Obstacles to return to work: Translation and cross-cultural \\ adaptation of the questionnaire to the Brazilian context
}

Daniela Milani ${ }^{1}$

Ana Claudia de Souza ${ }^{1}$

Marcio Sussumu Hirayama ${ }^{2}$

Neusa Maria Costa Alexandre ${ }^{1}$

\footnotetext{
${ }^{1}$ Faculdade de Enfermagem, Universidade Estadual de Campinas. Cidade Universitária Zeferino Vaz, Barão Geraldo. 13083970 Campinas SP Brasil. danmilani84@gmail.com ${ }^{2}$ Programa de PósGraduação em Saúde Coletiva, Departamento de Medicina Preventiva, Escola Paulista de Medicina, Universidade Federal de São Paulo. São Paulo SP Brasil.
}

\begin{abstract}
The few existing questionnaires addressing return to work in Brazil are medical and/or psychological and do not examine work environment-related issues. The Obstacles to Return-to-Work Questionnaire (ORTWQ) is multidimensional, including biopsychosocial and environmental factors, and has proven useful in the return to work issue. The scope of this study is to describe the translation and cultural adaptation process of ORTWQ for use in the Brazilian context. It also discusses aspects related to work and the importance for health professionals to identify obstacles to return to work for occupational health vigilance. For the cultural adaptation process, there were five steps: translation, synthesis, back translation, evaluation by an expert committee and the pre-test process. Before the pre-test phase, the Content Validity Index was checked and was considered adequate when it was $\geq 0.8$. The expression "increase working hours" was withdrawn from the questionnaire, since the partial returnto-work regime is rare in Brazil. The sample for the pre-test involved 40 individuals. The average time for completing ORTWQ was 14 minutes and the Brazilian version of ORTWQ proved to be adequate. Further studies should assess psychometric qualities of the questionnaire.
\end{abstract}

Key words Translation, Musculoskeletal diseases, Return to work, Questionnaires, Occupational health surveillance
Resumo Os raros questionários existentes no Brasil que abordam retorno ao trabalho são físicos elou psicológicos e não abrangem questões relativas ao ambiente de trabalho. $O$ Obstacles to Return-to-Work Questionnaire (ORTWQ) é multidimensional, inclui fatores biopsicossociais, ambientais e tem se mostrado útil como preditor de retorno ao trabalho. Este estudo tem como objetivo discutir a importância, para a Vigilância em Saúde do Trabalhador, de questionários que identificam os obstáculos para retorno ao trabatho, bem como traduzir e adaptar culturalmente o ORTWQ para uso no contexto brasileiro. Cinco etapas foram seguidas para a adaptação cultural: tradução, sintese, retrotradução, avaliação por comitê de especialistas e pré-teste. Antes do pré-teste, $o$ Índice de Validade de Conteúdo foi verificado e considerado adequado quando $\geq 0,8$. Foi retirado do questionário, o termo "aumentar as horas de trabalho", uma vez que o regime de retorno parcial ao trabalho é raro no Brasil. Participaram do pré-teste 40 sujeitos. A versão brasileira do ORTWQ mostrou-se adequada e o tempo médio para preenchimento foi de 14 minutos. Outros estudos devem avaliar as qualidades psicométricas desse questionário.

Palavras-chave Tradução, Doenças musculosqueléticas, Retorno ao trabalho, Questionários, Vigilância em saúde do trabalhador 


\section{Introdução}

O Sistema de Informações de Agravos de Notificação (SINAN) aponta que o número de notificações dos agravos e doenças relacionadas ao trabalho no Brasil passou de pouco mais de 40.000, em 2007, para cerca de 150.000, em 2014. Tais notificações estão relacionadas a acidentes graves e fatais, acidentes com exposição a material biológico, câncer, dermatoses, LER/DORT, entre outros. Embora o número de notificações seja crescente, discute-se que muitos casos ainda sejam subnotificados ${ }^{1}$

Nesse contexto, diversos setores, instituições e agentes individuais e coletivos estão envolvidos com a questão da saúde do trabalhador (ST). Segundo a Lei Orgânica do Sistema Único de Saúde (SUS) ${ }^{2}$, ST é entendida como "um conjunto de atividades que se destina, através das ações de vigilância epidemiológica e vigilância sanitária, à promoção e proteção da saúde dos trabalhadores, assim como visa à recuperação e reabilitação da saúde dos trabalhadores submetidos aos riscos e agravos advindos das condições de trabalho".

A ST, como área que integra o campo da Saúde Coletiva, apreende o trabalho como um dos principais determinantes sociais da saúde ${ }^{3}$ e desta forma preconiza ações interdisciplinares e intersetoriais. Como exemplo cita-se o decreto sobre a Política Nacional de Segurança e Saúde no Trabalho (PNSST) que aponta responsabilidades tanto do Ministério do Trabalho e Emprego, da Previdência Social e da Saúde ${ }^{4}$.

Com vistas ao desenvolvimento das ações de atenção integral à saúde do trabalhador no âmbito do SUS, algumas diretrizes também são definidas pela Política Nacional de Saúde do Trabalhador e da Trabalhadora ${ }^{5}$. Estas diretrizes enfatizam a Vigilância em Saúde do Trabalhador (VISAT) que, por sua vez, tem como objetivos a promoção, proteção da saúde dos trabalhadores e a redução da morbimortalidade decorrente dos processos laborais. As ações de vigilância são norteadas pela Rede Nacional de Atenção Integral à Saúde do Trabalhador (Renast) que é composta pelos Centros de Referência em Saúde do Trabalhador (Cerest).

No entanto, estudiosos argumentam ${ }^{6}$ que mesmo com a presença de suporte legal das políticas, a Renast pode ser vista como uma "rede que não enreda". Há limitações quanto à estrutura, financiamentos e gestão com dependência de outras instâncias que não têm a atenção integral da ST como foco principal ${ }^{6}$.

Desta forma, um desafio a ser enfrentado coletivamente refere-se à união de saberes diversos e de forma pluri-institucional em que exista um engajamento do poder público, da sociedade civil e de centros de pesquisas acadêmicas ${ }^{7}$. Neste sentido, o presente estudo intenciona contribuir nessa direção, à medida que oferece um instrumento de medida que aborda uma avaliação multidimensional do retorno ao trabalho relacionado à dor e aos distúrbios osteomusculares.

Os distúrbios osteomusculares incluem uma grande variedade de condições inflamatórias e degenerativas que afetam músculos, tendões, ligamentos, articulações, nervos periféricos e veias ${ }^{8-10}$. Nos estágios mais avançados, o indivíduo acometido pode apresentar limitação de movimentos, diminuição da capacidade para o trabalho e incapacidade para realizar suas atividades de vida diária ${ }^{9-11}$.

Distúrbios osteomusculares representam sério problema de saúde pública, afetam trabalhadores de diversas ocupações e estão entre os maiores responsáveis pela incapacidade no trabalho, absenteísmo e altos custos com pagamentos de indenizações em diversos países ${ }^{11-13}$.

As estatísticas brasileiras do Instituto Nacional de Seguro Social (INSS) também confirmam essa tendência mundial ${ }^{14}$. De acordo com os dados do Ministério da Previdência Social, no ano de 2013, de todos os novos benefícios auxílio-doença previdenciários concedidos, $18.7 \%$ foram devido aos distúrbios osteomusculares ${ }^{15}$. Com relação à concessão dos benefícios de auxílio doença acidentários, 25,4\% também foram devido a esses agravos ${ }^{16}$. É importante enfatizar que essas estatísticas se referem somente aos novos casos e isso representa em números absolutos aproximadamente 480.000 novos casos e um gasto referente a benefícios do INSS de mais de 500 milhões de reais no ano de $2012^{14}$.

Diversos são os fatores do ambiente laboral que podem representar riscos tanto para o desenvolvimento dos distúrbios osteomusculares como para a dor e/ou para a incapacidade. Dentre eles: fatores biomecânicos, organizacionais do local de trabalho, fatores psicossociais e características individuais ${ }^{8,17-23}$.

Além de representarem risco para a dor e incapacidade, estes fatores também têm sido reconhecidos como importantes determinantes de retorno ao trabalho, pois podem representar obstáculos para retorno ao trabalho em trabalhadores afastados por doenças ${ }^{8,18,20-23}$. Também são descritos como elementos que dificultam o retorno ao trabalho: a fadiga, a ansiedade social, o prognóstico próprio do trabalhador e/ou situação de stress familiar ${ }^{20}$.

O longo período de afastamento e a demora no retorno à vida laboral afetam significativa- 
mente tanto o aspecto econômico como o bem -estar individual e por isso representam problemas críticos para muitas sociedades ${ }^{24,25}$. Diante disso, estratégias e pesquisas têm sido desenvolvidas com o objetivo de prevenir a incapacidade para o trabalho, diminuir os custos dela decorrentes e promover a reabilitação dos trabalhadores incapacitados para que estes possam retornar ao trabalho ${ }^{24}$.

No entanto, mesmo com esses avanços e esforços, as taxas de incapacidade para o trabalho continuam a crescer e os custos associados aumentam drasticamente. Pesquisas ${ }^{4,26}$ apontam que isto tem acontecido porque a ênfase dos profissionais envolvidos com saúde ocupacional está ainda direcionada para intervenções menos efetivas. Ou seja, embora já se saiba que tanto os fatores internos (idade, gênero, estilo de vida, escolaridade, dor, etc.) como os externos (aspectos ocupacionais, suporte familiar e social, etc.) estão relacionados com o retorno ao trabalho, observase que muitas intervenções são implementadas no sentido de modificar apenas os fatores individuais e muito pouco tem sido feito com relação às modificações de fatores externos ${ }^{24,26}$.

Sabe-se que a utilização de intervenções e/ ou tratamentos inapropriados para pessoas com incapacidade e/ou com dor persistente resultam em altos custos ${ }^{27-29}$, enquanto intervenções apropriadas podem reduzir pela metade a média de tempo de incapacidade das pessoas que estão afastadas do trabalho ${ }^{24}$.

Sendo assim, identificar precocemente fatores e barreiras relacionadas ao retorno ao trabalho é essencial para que possam ser planejadas intervenções apropriadas que diminuam os longos períodos de incapacidade e aumentem as taxas de retorno ao trabalho ${ }^{13,27,28,30-32}$. Além disso, configura-se como uma ação integral, que contribui com a dimensão não só curativa e preventiva da VISAT como também na promoção da saúde. Ou seja, a identificação desses fatores informa a intervenção nos locais, processos e formas de organização do trabalho, interrompendo o ciclo de doença, afastamento, retorno, ou até mesmo a morte no trabalho.

A literatura aponta alguns métodos disponíveis para mensuração da incapacidade, do retorno ao trabalho e discute que o processo de retorno ao trabalho pode ser influenciado positivamente pela restauração funcional, pela reabilitação biopsicossocial e pela identificação de fatores de risco que podem ser obstáculos para este processo ${ }^{24,33,34}$

Pesquisadores $^{12}$ recomendam que estudos que identifiquem as barreiras e/ou facilitadores para retorno ao trabalho sejam realizadas para que medidas apropriadas possam ser implementadas. Outros ${ }^{24}$ sugerem que seja providenciada uma ampla base científica com estudos que possam proporcionar ferramentas aplicáveis e baseadas em evidências. Estudos também aler$\operatorname{tam}^{7,35}$ para que a valorização da percepção e das ações dos trabalhadores sejam consideradas, bem como a adoção de referenciais teóricos que possibilitem enxergar de forma ampla e multifacetada o trabalho contemporâneo a fim de evitar produção de indicadores simplistas e controversos para uma realidade complexa e permeada de interesses conflituosos.

Diante desse contexto, questionários com adequadas propriedades psicométricas que avaliam os obstáculos para retorno ao trabalho, que identificam fatores preditivos, e que sejam viáveis podem ser úteis ${ }^{18,36}$. Embora todo instrumento de autorrelato apresente suas limitações, muitas qualidades foram identificadas no Obstacles to Return-to-Work Questionnaire (ORTWQ). Este questionário foi desenvolvido originalmente por pesquisadores da Suécia e demonstrou validade e confiabilidade satisfatórias quando aplicado a trabalhadores afastados do trabalho devido a distúrbios osteomusculares naquele país ${ }^{18,20}$.

A avaliação e/ou identificação dos obstáculos para retorno ao trabalho é assunto pouco estudado no Brasil. Muitos dos questionários existentes ainda são estritamente médico-centrados ou psicológicos, abordam muitas vezes somente questões físicas e/ou psicológicas da dor, incapacidade, e raramente incluem questões relacionadas ao ambiente de trabalho ${ }^{20}$.

Desta forma, a disponibilidade de um questionário com as características do ORTWQ no Brasil pode ser de grande utilidade tanto para o fortalecimento das ações de VISAT, por meio dos CERESTs e serviços de todos os níveis de atenção, bem como para pesquisadores envolvidos com questões de saúde ocupacional e reabilitação. Este estudo teve como objetivo traduzir, adaptar culturalmente o ORTWQ e apresentar a sua versão para o contexto brasileiro.

\section{Métodos}

\section{O Instrumento}

O Obstacles to Return-to-Work Questionnai$r e^{20}$ foi desenvolvido originalmente na língua sueca e está disponível também em inglês ${ }^{20}$. O questionário contém 55 itens dispostos em nove domínios que por sua vez são organizados em 
três partes: I- Intensidade da dor e depressão; II-Obstáculos para retorno ao trabalho no ambiente laboral e na família; III-Motivação para retorno ao trabalho; (Figura 1). Para cada item, o indivíduo deve assinalar sua resposta em uma escala do tipo Likert de sete pontos que podem variar de " $0=$ nenhuma" a " $6=$ muita"; " $0=$ nunca" a " $6=$ sempre"; " $0=$ nada" a " $6=$ muito"; " $0=$ discordo totalmente" a " $6=$ concordo totalmente", dentre outras.

A pontuação do questionário por meio do escore dos domínios pode ser utilizada para identificar o valor preditivo que cada um dos domínios exerce no retorno ao trabalho. Embora consideremos essa a melhor maneira de pontuá-lo, o estudo que desenvolveu o ORTWQ ${ }^{12}$ faz menção apenas a pontuação pelo escore total.
Tanto para o cálculo do escore total quanto para o escore por domínios, deve-se atentar para os itens que foram formulados em ordem negativa tais como: itens $2,5,9,13,18,27,31$ e 32 da parte II e itens 1, 3, 4, 5 e 6 referentes à parte III. Estes itens devem ser revertidos antes de serem somados aos itens formulados positivamente. $\mathrm{Ou}$ seja, para os itens formulados em ordem negativa, deve-se considerar: $0=6,1=5,2=4,3=3,4$ $=2,5=1$ e $6=0$.

Após reversão desses itens, o escore de cada domínio pode variar de 0 a 6 e é calculado pela média aritmética das respostas de cada item. Assim, quanto mais próximo de seis o escore, maiores as chances do respectivo domínio influenciar negativamente o retorno ao trabalho. Já o cálculo do escore total (soma de todos os itens) pode

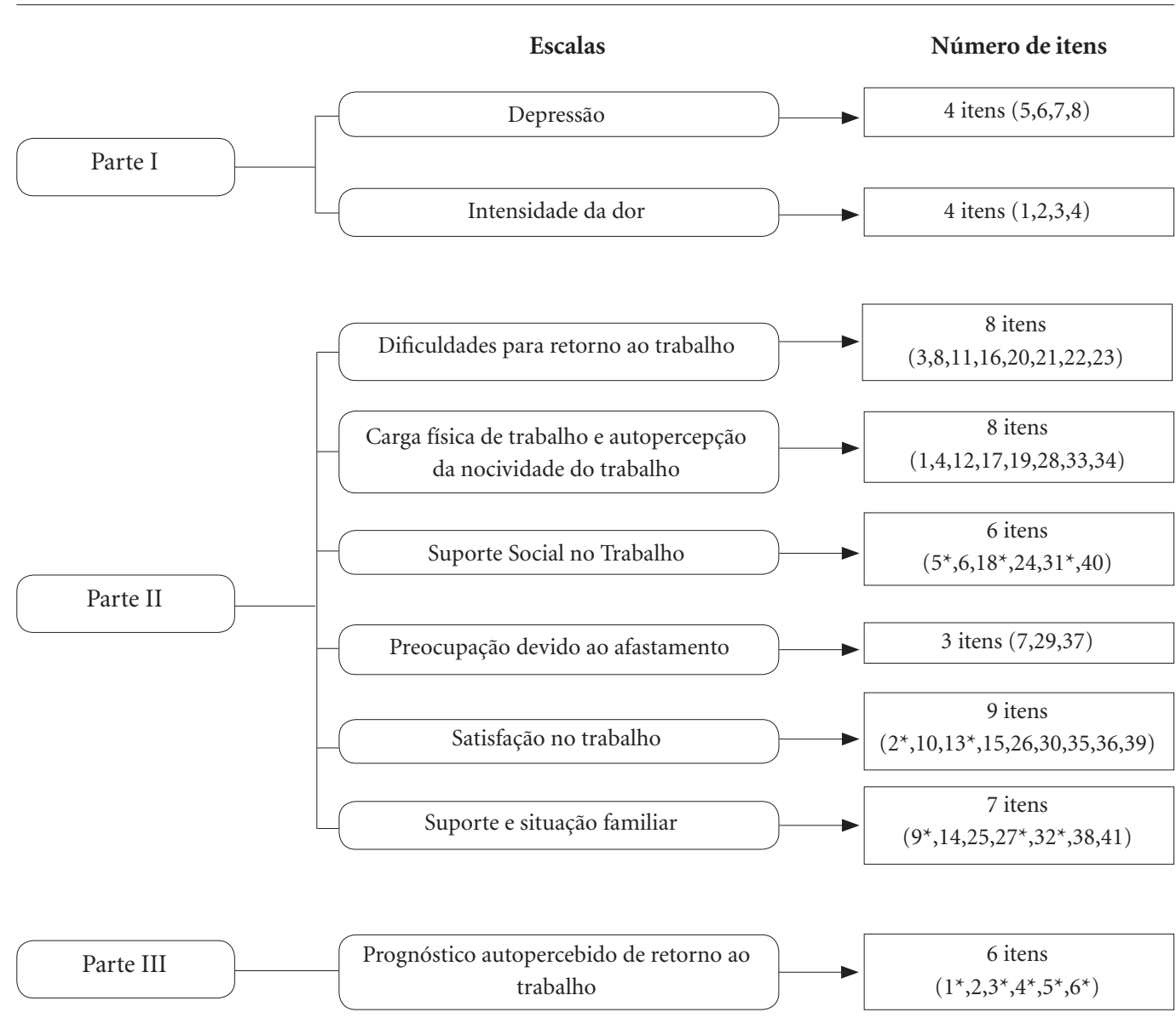

${ }^{\star}$ Itens que devem ser revertidos antes do cálculo dos escores

Figura 1. A divisão do Obstacles to Return-to-Work Questionnaire em suas partes, domínios e os respectivos itens. (Para o cálculo dos escores as respostas dos itens marcados com “»” devem ser revertidas). 
O processo metodológico de adaptação cultural do ORTWQ foi realizado conforme recomendações publicadas na literatura internacional (Figura 2) 37,38 .

\section{Etapas da adaptação cultural}

\section{Tradução inicial}

A versão em inglês do ORTWQ foi traduzida para o português de forma independente por dois tradutores bilíngues, cuja língua materna era o português. Seguindo recomendações, um dos tradutores tinha experiência na área de saúde e estava ciente dos objetivos do questionário, e o segundo não pertencia à área de saúde nem foi orientado quanto aos objetivos do questionário. Ao final dessa etapa foram obtidas duas versões em português do instrumento.

\section{Síntese das traduções}

Com objetivo de confeccionar uma única versão, as duas traduções para o português foram confrontadas pelos tradutores juntamente com as pesquisadoras para que houvesse um consenso entre aqueles itens que estavam discrepantes.

\section{Retrotradução}

A versão síntese foi traduzida de volta para o inglês por dois tradutores bilíngues que não participaram da primeira etapa de tradução e cuja língua materna era inglesa. Estes realizaram as

retrotraduções de forma independente, sem informações sobre conceitos ou propósitos abordados pelo instrumento e sem conhecimento da sua versão original. Esta fase teve como objetivo verificar possíveis erros, discrepâncias no conteúdo entre o instrumento original e a versão traduzida.

\section{Comitê de especialistas}

Esta fase tem como objetivo garantir a compreensão e a equivalência cultural da versão final do instrumento. O comitê foi composto por oito peritos bilíngues com experiência em: adaptação cultural de instrumentos, saúde ocupacional, linguística, psicologia, ergonomia e fisioterapia.

Cada membro recebeu: I-convite com orientações para participação no estudo; II-versão original do instrumento; III-duas versões traduzidas para o português; IV-versão síntese; V- versões retrotraduzidas; VI- instrumento para avaliação das equivalências conceitual, idiomática, cultural e semântica das versões.

Após avaliação dos especialistas, verificou-se o Índice de Validade de Conteúdo (IVC) para cada um dos itens do instrumento. Esse índice mede a proporção de juízes que está em concordância sobre determinados aspectos do instrumento e de seus itens. Foram considerados adequados os itens que obtiveram IVC maior ou igual a $0,8^{39}$.

\section{Pré-teste}

Esta fase avalia se a compreensão dos itens da versão adaptada mantém a sua equivalência com o original durante a aplicação do questionário, bem como a facilidade de compreensão do questionário pelos respondentes.

Participaram do pré-teste 40 sujeitos com média de idade de 42,8 $(11,2)$ anos (Tabela 1). Após responderem ao questionário, os participantes

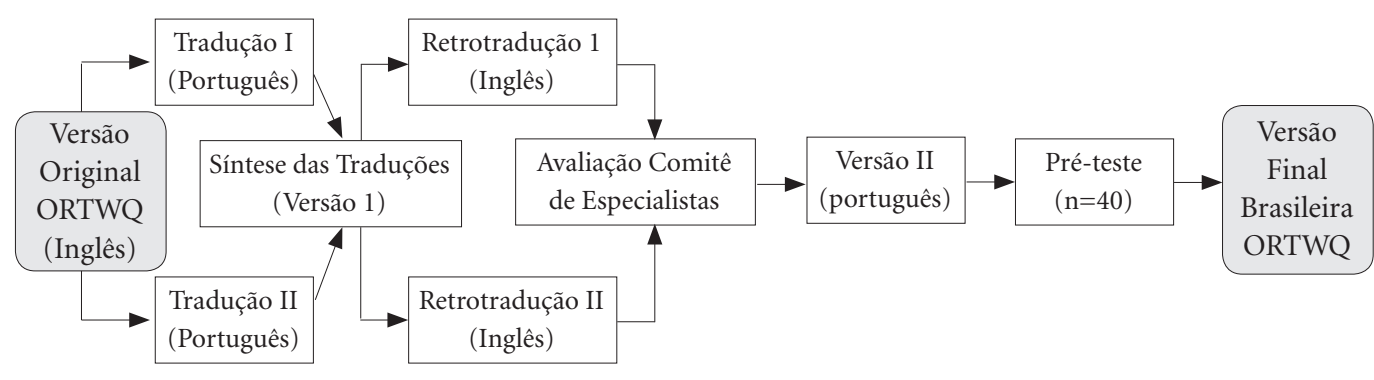

Figura 2. Processo de adaptação cultural do Obstacles to Return-to-Work Questionnaire para o Brasil. 
Tabela 1. Características gerais da amostra do préteste do Obstacles to Return-to-Work Questionnaire adaptado para o Brasil

\begin{tabular}{llrr}
\hline \multicolumn{1}{c}{ Variável } & \multicolumn{1}{c}{ Categoria } & n & \% \\
\hline Total & & 40 & 100 \\
Gênero & Masculino & 21 & 52,5 \\
& Feminino & 19 & 47,5 \\
Faixa etária & 18 a 35 anos & 13 & 32.5 \\
& 36 a 59 anos & 26 & 65.0 \\
& 60 anos ou mais & 1 & 2.5 \\
Estado civil & Solteiro & 3 & 7,5 \\
& Casado & 26 & 65,0 \\
& Viúvo & 5 & 12,5 \\
& Vive com companheiro & 6 & 15,0 \\
Escolaridade & Não estudou & 2 & 5,0 \\
& 4 anos & 7 & 17,5 \\
& 8 anos & 6 & 15,0 \\
& 11 anos & 17 & 42,5 \\
& $>11$ anos & 8 & 20,0 \\
\hline
\end{tabular}

também foram entrevistados pela pesquisadora com a finalidade de identificar dificuldades percebidas com relação às escalas de respostas, dificuldades de compreensão dos enunciados, dos termos e/ou palavras. A amostra foi por conveniência e composta por pacientes de duas clínicas de fisioterapia situadas no interior do estado de São Paulo, sendo uma privada e outra pública.

Os critérios de inclusão para participação foram: idade superior a 18 anos e estar afastado do trabalho devido a distúrbios osteomusculares.

\section{Aspectos éticos}

O presente estudo foi aprovado pelo Comitê de Ética em Pesquisa da Faculdade de Ciências Médicas da Unicamp. Os autores que desenvolveram o ORTWQ concederam autorização para que a tradução e adaptação cultural deste instrumento pudessem ser realizadas no Brasil.

\section{Resultados}

Todos os itens pertencentes à parte I e III do questionário obtiveram IVC $=1,00$. Na parte II, $78,6 \%$ dos itens obtiveram IVC $=1,00$ e $16,7 \%$ IVC $=0,88$. Apenas os itens 29 e 40 apresentaram IVC menor que 0,80 (0,63 e 0,75 respectivamente) e precisaram de maiores alterações.

Pequenas alterações também foram sugeridas para alguns outros itens no sentido de facilitar entendimento dos participantes. Estas se deram principalmente com relação à ordem gramatical, inversão de palavras ou substituição de alguma palavra por sinônimo correspondente.

Durante avaliação do instrumento pelo comitê de especialistas foi sugerida a retirada da expressão “aumentar as horas de trabalho". Essa expressão estava presente nos itens: 3, 8, 37 da parte II, e itens 1, 2, 4 e 5 da parte III. Embora esses itens tenham apresentado IVC maior que 0,88 , optou-se pela retirada dessa expressão uma vez que no Brasil o regime de retorno parcial ao trabalho não acontece.

Durante o pré-teste outros itens também suscitaram dúvidas aos respondentes. Estes se referiam principalmente ao significado de algumas palavras e expressões, como por exemplo: "fadiga", "entediado", "variado e estimulante”, "quão", "situação familiar", "prejudicial”.

Tais itens foram discutidos novamente com membros do comitê de especialistas para serem melhorados. No Quadro 1 estão apresentados os itens aos quais se realizou algum tipo de alteração seja na fase de avaliação dos especialistas como após o pré-teste.

Após as modificações sugeridas pelo comitê de especialistas e pequenas alterações após préteste, obteve-se a versão final do ORTWQ para uso no Brasil conforme apresentado no Quadro 2.

O tempo médio de preenchimento da versão brasileira do ORTWQ foi de 14,1 $(4,85)$ minutos. Sendo o máximo de tempo 26 minutos e o mínimo 8 minutos.

\section{Discussão}

Pesquisadores $^{18}$ apontam o ORTWQ como um instrumento que possui muitas vantagens como: ser de domínio público, ser multidimensional, apresentar validade e confiabilidade adequadas nas amostras em que foi utilizado e facilidade no cálculo dos escores. Além disso, esse questionário foi incluído em duas revisões sistemáticas da literatura ${ }^{28,40}$ que fortemente recomendaram seu uso para avaliar questões ocupacionais múltiplas.

No entanto, assim como todo questionário, o ORTWQ também apresenta suas limitações. Por contemplar 55 itens, o questionário pode ser visto em um primeiro momento como longo e não tão adequado para ser utilizado em serviços de atenção primária à saúde ${ }^{18}$. $\mathrm{O}$ tempo para administração tem sido aproximadamente 20 minutos em sua versão original ${ }^{18}$ e na versão brasileira aproximadamente 14 minutos. 
Quadro 1. Itens do ORTWQ que apresentaram algum tipo de alteração após avaliação do comitê de especialistas ou após pré-teste.

\begin{tabular}{|c|c|c|c|c|}
\hline $\begin{array}{l}\text { Itens do } \\
\text { ORTWQ }\end{array}$ & Versão Original & Síntese das traduções & $\begin{array}{c}\text { Versão após } \\
\text { Comitê de especialistas }\end{array}$ & $\begin{array}{c}\text { Versão Final } \\
\text { depois do pré-teste }\end{array}$ \\
\hline $\begin{array}{l}1 \\
\text { parte I }\end{array}$ & $\begin{array}{l}\text { How much pain have } \\
\text { you had during the last } \\
\text { week? }\end{array}$ & $\begin{array}{l}\text { Quanta dor você teve na } \\
\text { semana passada? }\end{array}$ & $\begin{array}{l}\text { Quanta dor você tem } \\
\text { sentido durante esta } \\
\text { última semana? }\end{array}$ & $\begin{array}{l}\text { Manteve-se a mesma } \\
\text { versão pós-comitê de } \\
\text { especialista. }\end{array}$ \\
\hline $\begin{array}{l}6 \\
\text { parte I }\end{array}$ & $\begin{array}{l}\text { How dejected have } \\
\text { you felt during the last } \\
\text { week? }\end{array}$ & $\begin{array}{l}\text { O quanto deprimido você se } \\
\text { sentiu na semana passada? }\end{array}$ & $\begin{array}{l}\text { Quão desanimado você } \\
\text { tem se sentido durante } \\
\text { esta última semana? }\end{array}$ & $\begin{array}{l}\text { Quanto desanimado } \\
\text { você tem se sentido } \\
\text { durante esta última } \\
\text { semana? }\end{array}$ \\
\hline $\begin{array}{l}7 \\
\text { parte I }\end{array}$ & $\begin{array}{l}\text { How dejected have you } \\
\text { felt, on average, during } \\
\text { the last three months? }\end{array}$ & $\begin{array}{l}\text { O quanto deprimido, em } \\
\text { media, você tem se sentido } \\
\text { nos últimos três meses? }\end{array}$ & $\begin{array}{l}\text { Em média, quão } \\
\text { desanimado você tem se } \\
\text { sentido nos últimos três } \\
\text { meses? }\end{array}$ & $\begin{array}{l}\text { Em média, quanto } \\
\text { você tem se sentido } \\
\text { desanimado nos últimos } \\
\text { três meses? }\end{array}$ \\
\hline $\begin{array}{l}3 \\
\text { parte II }\end{array}$ & $\begin{array}{l}\text { On return to work } \\
\text { / increase in work } \\
\text { time, fatigue will be a } \\
\text { problem for me. }\end{array}$ & $\begin{array}{l}\text { Ao voltar ao trabalho e/ } \\
\text { ou aumentar as horas de } \\
\text { trabalho, a fadiga será um } \\
\text { problema para mim }\end{array}$ & $\begin{array}{l}\text { Ao retornar ao trabalho, a } \\
\text { fadiga será um problema } \\
\text { para mim. }\end{array}$ & $\begin{array}{l}\text { Ao retornar ao trabalho, } \\
\text { a fadiga (cansaço) será } \\
\text { um problema para mim. }\end{array}$ \\
\hline $\begin{array}{l}4 \\
\text { parte II }\end{array}$ & $\begin{array}{l}\text { I have too much to do } \\
\text { at work. }\end{array}$ & $\begin{array}{l}\text { Tenho muitas coisas para } \\
\text { fazer no meu trabalho. }\end{array}$ & $\begin{array}{l}\text { Eu tenho coisas demais } \\
\text { para fazer no meu } \\
\text { trabalho. }\end{array}$ & $\begin{array}{l}\text { Manteve-se a mesma } \\
\text { versão pós-comitê de } \\
\text { especialista }\end{array}$ \\
\hline $\begin{array}{l}7 \\
\text { parte II }\end{array}$ & $\begin{array}{l}\text { I worry about what my } \\
\text { work colleagues think } \\
\text { about my sick leave. }\end{array}$ & $\begin{array}{l}\text { Me preocupo com o que } \\
\text { meus colegas de trabalho } \\
\text { pensam sobre minha licença } \\
\text { por doença }\end{array}$ & $\begin{array}{l}\text { Eu me preocupo com } \\
\text { o que meus colegas de } \\
\text { trabalho pensam sobre } \\
\text { minha licença-saúde. }\end{array}$ & $\begin{array}{l}\text { Manteve-se a mesma } \\
\text { versão pós-comitê de } \\
\text { especialista. }\end{array}$ \\
\hline $\begin{array}{l}8 \\
\text { parte II }\end{array}$ & $\begin{array}{l}\text { Increased ache will } \\
\text { be a problem for me } \\
\text { on return to work / } \\
\text { increase in work time. }\end{array}$ & $\begin{array}{l}\text { O aumento da dor será } \\
\text { um problema para mim } \\
\text { ao retornar ao trabalho e/ } \\
\text { ou ao aumentar as horas de } \\
\text { trabalho }\end{array}$ & $\begin{array}{l}\text { O aumento da dor será } \\
\text { um problema para mim } \\
\text { quando eu retornar ao } \\
\text { trabalho. }\end{array}$ & $\begin{array}{l}\text { Manteve-se a mesma } \\
\text { versão pós-comitê de } \\
\text { especialista }\end{array}$ \\
\hline $\begin{array}{l}13 \\
\text { parte II }\end{array}$ & $\begin{array}{l}\text { My job is varied and } \\
\text { stimulating. }\end{array}$ & $\begin{array}{l}\text { Meu trabalho é variado e } \\
\text { estimulante }\end{array}$ & $\begin{array}{l}\text { Meu trabalho é variado e } \\
\text { estimulante }\end{array}$ & Meu trabalho é variado. \\
\hline $\begin{array}{l}14 \\
\text { parte II }\end{array}$ & $\begin{array}{l}\text { It's hard to find the } \\
\text { energy to work since my } \\
\text { family situation / social } \\
\text { situation is bad. }\end{array}$ & $\begin{array}{l}\text { É difícil encontrar energia } \\
\text { para trabalhar uma vez que } \\
\text { minha situação familiar/ } \\
\text { social é ruim. }\end{array}$ & $\begin{array}{l}\text { É difícil encontrar energia } \\
\text { para trabalhar, uma } \\
\text { vez que minha situação } \\
\text { familiar ou social é ruim. }\end{array}$ & $\begin{array}{l}\text { É difícil encontrar } \\
\text { energia para trabalhar } \\
\text { por causa dos meus } \\
\text { problemas familiares ou } \\
\text { sociais. }\end{array}$ \\
\hline $\begin{array}{l}25 \\
\text { parte II }\end{array}$ & $\begin{array}{l}\text { Since my children take } \\
\text { up so much energy, } \\
\text { it's hard to find the } \\
\text { strength to work. }\end{array}$ & $\begin{array}{l}\text { Meus filhos consomem } \\
\text { muito da minha energia e } \\
\text { por isso é difícil encontrar } \\
\text { forças para trabalhar. }\end{array}$ & $\begin{array}{l}\text { Meus filhos consomem } \\
\text { muito da minha energia e } \\
\text { por isso é difícil encontrar } \\
\text { forças para eu trabalhar. }\end{array}$ & $\begin{array}{l}\text { Minha família consome } \\
\text { muito da minha energia } \\
\text { e por isso é difícil } \\
\text { encontrar forças para } \\
\text { trabalhar. }\end{array}$ \\
\hline $\begin{array}{l}28 \\
\text { parte I }\end{array}$ & $\begin{array}{l}\text { My work is detrimental } \\
\text { to my health. }\end{array}$ & $\begin{array}{l}\text { Meu trabalho é prejudicial à } \\
\text { minha saúde. }\end{array}$ & $\begin{array}{l}\text { Meu trabalho é prejudicial } \\
\text { à minha saúde. }\end{array}$ & $\begin{array}{l}\text { Meu trabalho faz mal } \\
\text { para minha saúde. }\end{array}$ \\
\hline $\begin{array}{l}29 \\
\text { parte II }\end{array}$ & $\begin{array}{l}\text { It feels bad that I get } \\
\text { so far behind at work } \\
\text { when I'm on sick leave. }\end{array}$ & $\begin{array}{l}\text { Sinto-me mal por ficar } \\
\text { tão para trás no trabalho } \\
\text { quando estou de licença por } \\
\text { doença }\end{array}$ & $\begin{array}{l}\text { Quando estou de licença- } \\
\text { saúde, eu me sinto mal } \\
\text { por ficar tão atrasado com } \\
\text { meu trabalho. }\end{array}$ & $\begin{array}{l}\text { Manteve-se a mesma } \\
\text { versão pós-comitê de } \\
\text { especialista }\end{array}$ \\
\hline $\begin{array}{l}30 \\
\text { parte II }\end{array}$ & I feel bored by my work & $\begin{array}{l}\text { Sinto-me entediado com } \\
\text { meu trabalho }\end{array}$ & $\begin{array}{l}\text { Eu me sinto entediado } \\
\text { com meu trabalho. }\end{array}$ & $\begin{array}{l}\text { Eu me sinto entediado } \\
\text { (aborrecido) com meu } \\
\text { trabalho. }\end{array}$ \\
\hline
\end{tabular}


Quadro 1. continuação

\begin{tabular}{|c|c|c|c|c|}
\hline $\begin{array}{l}\text { Itens do } \\
\text { ORTWQ }\end{array}$ & Versão Original & Síntese das traduções & $\begin{array}{c}\text { Versão após } \\
\text { Comitê de especialistas }\end{array}$ & $\begin{array}{c}\text { Versão Final } \\
\text { depois do pré-teste }\end{array}$ \\
\hline $\begin{array}{l}37 \\
\text { parte II }\end{array}$ & $\begin{array}{l}\text { I have to work hard } \\
\text { when I get back / } \\
\text { increase my work } \\
\text { time to make up for } \\
\text { everything I missed } \\
\text { during sick leave. }\end{array}$ & $\begin{array}{l}\text { Tenho que trabalhar muito } \\
\text { quando retorno e/ou } \\
\text { aumento meu tempo de } \\
\text { trabalho para compensar } \\
\text { tudo o que perdi durante } \\
\text { minha licença por doença. }\end{array}$ & $\begin{array}{l}\text { Quando eu retorno ao } \\
\text { trabalho, eu preciso } \\
\text { trabalhar muito para } \\
\text { compensar tudo o que } \\
\text { perdi durante minha } \\
\text { licença-saúde. }\end{array}$ & $\begin{array}{l}\text { Manteve-se a mesma } \\
\text { versão pós-comitê de } \\
\text { especialista }\end{array}$ \\
\hline $\begin{array}{l}40 \\
\text { parte II }\end{array}$ & $\begin{array}{l}\text { It feels bad that my } \\
\text { work colleagues don't } \\
\text { understand my pain. }\end{array}$ & $\begin{array}{l}\text { Sinto-me mal por meus } \\
\text { colegas de trabalho não } \\
\text { compreenderem minha dor }\end{array}$ & $\begin{array}{l}\text { É ruim o fato dos meus } \\
\text { colegas de trabalho não } \\
\text { compreenderem minha } \\
\text { dor. }\end{array}$ & $\begin{array}{l}\text { Manteve-se a mesma } \\
\text { versão pós-comitê de } \\
\text { especialista }\end{array}$ \\
\hline $\begin{array}{l}41 \\
\text { parte II }\end{array}$ & $\begin{array}{l}\text { I need to stay home } \\
\text { because of my family } \\
\text { situation }\end{array}$ & $\begin{array}{l}\text { Preciso ficar em casa por } \\
\text { causa da minha situação } \\
\text { familiar. }\end{array}$ & $\begin{array}{l}\text { Eu preciso ficar em casa } \\
\text { por causa da minha } \\
\text { situação familiar. }\end{array}$ & $\begin{array}{l}\text { Eu preciso ficar em casa } \\
\text { por causa dos meus } \\
\text { problemas familiares. }\end{array}$ \\
\hline $\begin{array}{l}1 \\
\text { parte III }\end{array}$ & $\begin{array}{l}\text { How much chance } \\
\text { do you think there is } \\
\text { that you could return } \\
\text { to work / increase your } \\
\text { work time? }\end{array}$ & $\begin{array}{l}\text { O quanto de chance você } \\
\text { acha que existe de você } \\
\text { ser capaz de retornar ao } \\
\text { trabalho e/ou aumentar seu } \\
\text { tempo de trabalho? }\end{array}$ & $\begin{array}{l}\text { Na sua opinião, qual a } \\
\text { chance que existe de você } \\
\text { conseguir retornar ao } \\
\text { trabalho? }\end{array}$ & $\begin{array}{l}\text { Manteve-se a mesma } \\
\text { versão pós-comitê de } \\
\text { especialista }\end{array}$ \\
\hline $\begin{array}{l}2 \\
\text { parte III }\end{array}$ & $\begin{array}{l}\text { How do think it's going } \\
\text { to be to return to work } \\
\text { / increase your work } \\
\text { time? }\end{array}$ & $\begin{array}{l}\text { Como você acha que será } \\
\text { retornar ao trabalho/ } \\
\text { aumentar as horas de } \\
\text { trabalho? }\end{array}$ & $\begin{array}{l}\text { Como você acha que } \\
\text { será o seu retorno ao } \\
\text { trabalho? }\end{array}$ & $\begin{array}{l}\text { Manteve-se a mesma } \\
\text { versão pós-comitê de } \\
\text { especialista }\end{array}$ \\
\hline $\begin{array}{l}3 \\
\text { parte III }\end{array}$ & $\begin{array}{l}\text { How convinced are you } \\
\text { that you will recover? }\end{array}$ & $\begin{array}{l}\text { O quanto convencido você } \\
\text { está de que vai se recuperar? }\end{array}$ & $\begin{array}{l}\text { Quão convencido você } \\
\text { está de que você vai se } \\
\text { recuperar? }\end{array}$ & $\begin{array}{l}\text { O quanto convencido } \\
\text { você está de que você vai } \\
\text { se recuperar? }\end{array}$ \\
\hline $\begin{array}{l}4 \\
\text { parte III }\end{array}$ & $\begin{array}{l}\text { How much chance is } \\
\text { there that you will be } \\
\text { able to return to work / } \\
\text { increase your work time } \\
\text { within six months? }\end{array}$ & $\begin{array}{l}\text { Quanto de chance existe } \\
\text { de você ter condições de } \\
\text { retornar ao trabalho e/ } \\
\text { ou aumentar seu tempo } \\
\text { de trabalho dentro de seis } \\
\text { meses }\end{array}$ & $\begin{array}{l}\text { Quanta chance você } \\
\text { acha que existe de você } \\
\text { ser capaz de retornar ao } \\
\text { trabalho nos próximos } \\
\text { seis meses? }\end{array}$ & $\begin{array}{l}\text { Manteve-se a mesma } \\
\text { versão pós-comitê de } \\
\text { especialista }\end{array}$ \\
\hline $\begin{array}{l}5 \\
\text { parte III }\end{array}$ & $\begin{array}{l}\text { How do you feel } \\
\text { when you think about } \\
\text { your possibilities for } \\
\text { returning to work / } \\
\text { increasing your work } \\
\text { time? }\end{array}$ & $\begin{array}{l}\text { Como você se sente } \\
\text { quando pensa em suas } \\
\text { possibilidades de retornar } \\
\text { ao trabalho e/ou aumentar } \\
\text { seu tempo de trabalho? }\end{array}$ & $\begin{array}{l}\text { Como você se sente } \\
\text { quando pensa sobre as } \\
\text { suas possibilidades de } \\
\text { retornar ao trabalho? }\end{array}$ & $\begin{array}{l}\text { Manteve-se a mesma } \\
\text { versão pós-comitê de } \\
\text { especialista }\end{array}$ \\
\hline
\end{tabular}

Manter a validade de conteúdo de um instrumento como o ORTWQ no mesmo nível conceitual é um desafio. Especialmente entre culturas tão diferentes como é o caso de Suécia e Brasil. O processo de adaptação cultural é longo, exige a participação de diversos tipos de profissionais e é muito mais do que uma simples tradução ${ }^{38}$.

Embora tenham sido necessárias alterações devido às diferentes culturas e contextos sociopolíticos entre Brasil e Suécia, pode-se afirmar que o processo de tradução e adaptação cultural do ORTWQ para o contexto brasileiro foi bem- sucedido. Mesmo após alterações, a versão brasileira do questionário demonstrou equivalências conceitual, semântica e idiomática satisfatórias quando comparada com a versão original sueca.

A principal diferença percebida esteve relacionada ao fato de na Suécia existir o regime de retorno parcial ao trabalho. No contexto dos países nórdicos, esse regime é comum e tem sido objeto de vários estudos ${ }^{41,42}$, enquanto no Brasil esse regime e/ou política é inexistente.

Uma vez que as propriedades psicométricas de um instrumento são inerentes àquela amos- 
Quadro 2. Versão Brasileira do Questionário sobre Obstáculos para retorno ao trabalho

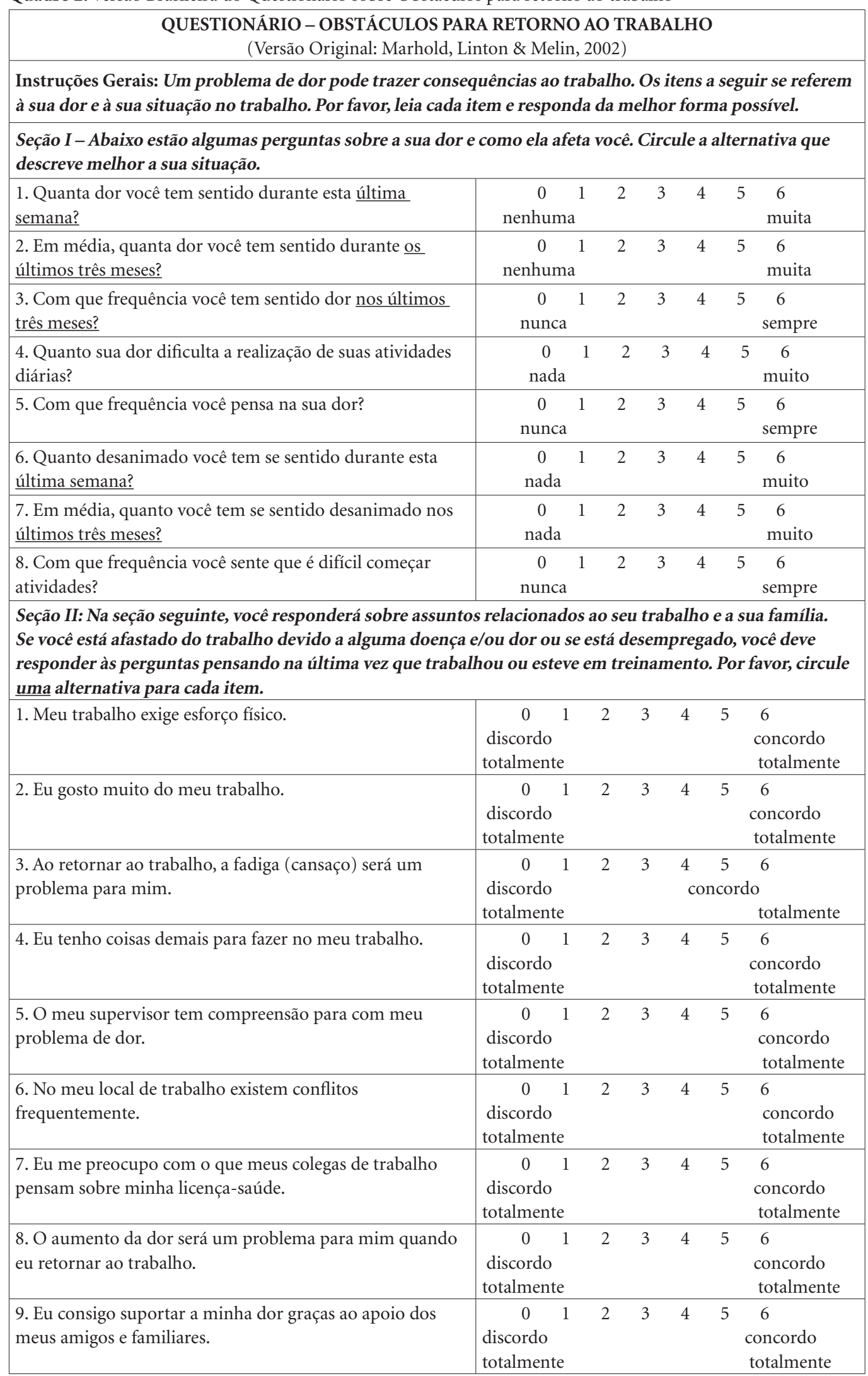


Quadro 2. continuação

\begin{tabular}{|c|c|c|c|c|c|c|}
\hline 10. Minhas tarefas de trabalho são entediantes/chatas. & \begin{tabular}{|c}
0 \\
discordo \\
totalmente
\end{tabular} & 2 & 3 & 4 & & $\begin{array}{l}6 \\
\text { concordo } \\
\text { totalmente }\end{array}$ \\
\hline $\begin{array}{l}\text { 11. Depois do trabalho, não tenho energia para fazer mais } \\
\text { nada, só descansar. }\end{array}$ & $\begin{array}{c}0 \\
\text { discordo } \\
\text { totalmente }\end{array}$ & 2 & 3 & 4 & 5 & $\begin{array}{l}6 \\
\text { concordo } \\
\text { totalmente }\end{array}$ \\
\hline $\begin{array}{l}\text { 12. Não vou conseguir reduzir meu tempo de licença-saúde } \\
\text { porque meu trabalho exige muito esforço físico. }\end{array}$ & $\begin{array}{c}0 \\
\text { discordo } \\
\text { totalmente }\end{array}$ & 2 & 3 & 4 & 5 & $\begin{array}{l}6 \\
\text { concordo } \\
\text { totalmente }\end{array}$ \\
\hline 13. Meu trabalho é variado. & $\begin{array}{c}0 \\
\text { discordo } \\
\text { totalmente }\end{array}$ & 2 & 3 & 4 & 5 & $\begin{array}{l}6 \\
\text { concordo } \\
\text { totalmente }\end{array}$ \\
\hline $\begin{array}{l}\text { 14. É difícil encontrar energia para trabalhar por causa dos } \\
\text { meus problemas familiares ou sociais. }\end{array}$ & $\begin{array}{c}0 \\
\text { discordo } \\
\text { totalmente }\end{array}$ & 2 & 3 & 4 & & $\begin{array}{l}6 \\
\text { concordo } \\
\text { totalmente }\end{array}$ \\
\hline 15. Eu gostaria de mudar as minhas tarefas de trabalho. & $\begin{array}{c}0 \\
0 \\
\text { discordo } \\
\text { totalmente }\end{array}$ & 2 & 3 & 4 & 5 & $\begin{array}{l}6 \\
\text { concordo } \\
\text { totalmente }\end{array}$ \\
\hline $\begin{array}{l}\text { 16. Eu tenho passado tempo com menos amigos e } \\
\text { conhecidos desde que fiquei de licença-saúde. }\end{array}$ & $\begin{array}{c}0 \\
\text { discordo } \\
\text { totalmente }\end{array}$ & 2 & 3 & 4 & & $\begin{array}{l}6 \\
\text { concordo } \\
\text { totalmente }\end{array}$ \\
\hline 17. O meu trabalho é a causa da minha dor. & $\begin{array}{c}0 \\
0 \\
\text { discordo } \\
\text { totalmente }\end{array}$ & 2 & 3 & 4 & & $\begin{array}{l}6 \\
\text { concordo } \\
\text { totalmente }\end{array}$ \\
\hline $\begin{array}{l}\text { 18. Meu supervisor tenta me apoiar e tornar as coisas mais } \\
\text { fáceis para mim no meu local de trabalho. }\end{array}$ & $\begin{array}{c}0 \\
\text { discordo } \\
\text { totalmente }\end{array}$ & 2 & 3 & 4 & 5 & $\begin{array}{l}6 \\
\text { concordo } \\
\text { totalmente }\end{array}$ \\
\hline $\begin{array}{l}\text { 19. Os movimentos repetitivos, (por exemplo, com os } \\
\text { braços e mãos) que fazem parte do meu trabalho, agravam } \\
\text { a minha dor. }\end{array}$ & $\begin{array}{c}0 \quad 1 \\
\text { discordo } \\
\text { totalmente }\end{array}$ & 2 & 3 & 4 & & $\begin{array}{l}6 \\
\text { concordo } \\
\text { totalmente }\end{array}$ \\
\hline $\begin{array}{l}\text { 20. Eu tive que desistir de atividades de lazer por causa da } \\
\text { minha dor. }\end{array}$ & $\begin{array}{c}0 \\
\text { discordo } \\
\text { totalmente }\end{array}$ & 2 & 3 & 4 & & $\begin{array}{l}6 \\
\text { concordo } \\
\text { totalmente }\end{array}$ \\
\hline $\begin{array}{l}\text { 21. Eu estou doente e/ou incapacitado demais para } \\
\text { continuar no meu trabalho. }\end{array}$ & $\begin{array}{c}0 \quad 1 \\
\text { discordo } \\
\text { totalmente }\end{array}$ & 2 & 3 & 4 & 5 & $\begin{array}{l}6 \\
\text { concordo } \\
\text { totalmente }\end{array}$ \\
\hline $\begin{array}{l}\text { 22. A vida fica sem sentido quando eu não tenho energia } \\
\text { para realizar mais nada após o trabalho. }\end{array}$ & $\begin{array}{c}0 \quad 1 \\
\text { discordo } \\
\text { totalmente }\end{array}$ & 2 & 3 & 4 & 5 & $\begin{array}{l}6 \\
\text { concordo } \\
\text { totalmente }\end{array}$ \\
\hline 23. Eu preciso descansar quando a minha dor aumenta. & $\begin{array}{c}0 \quad 1 \\
\text { discordo } \\
\text { totalmente }\end{array}$ & 2 & 3 & 4 & & $\begin{array}{l}6 \\
\text { concordo } \\
\text { totalmente }\end{array}$ \\
\hline 24. O meu local de trabalho tem um clima tenso. & $\begin{array}{c}0 \\
\text { discordo } \\
\text { totalmente }\end{array}$ & 2 & 3 & 4 & 5 & $\begin{array}{l}6 \\
\text { concordo } \\
\text { totalmente }\end{array}$ \\
\hline $\begin{array}{l}\text { 25. Minha família consome muito da minha energia e por } \\
\text { isso é difícil encontrar forças para eu trabalhar. }\end{array}$ & $\begin{array}{c}0 \\
\text { discordo } \\
\text { totalmente }\end{array}$ & 2 & 3 & 4 & 5 & $\begin{array}{l}6 \\
\text { concordo } \\
\text { totalmente }\end{array}$ \\
\hline $\begin{array}{l}\text { 26. Aquilo que eu faço fora do meu horário de serviço } \\
\text { parece mais importante do que meu trabalho. }\end{array}$ & $\begin{array}{c}0 \\
\text { discordo } \\
\text { totalmente }\end{array}$ & 2 & 3 & 4 & & $\begin{array}{l}6 \\
\text { concordo } \\
\text { totalmente }\end{array}$ \\
\hline $\begin{array}{l}\text { 27. Eu sinto que meus familiares e amigos tem } \\
\text { compreensão com a minha situação. }\end{array}$ & $\begin{array}{c}0 \\
\text { discordo } \\
\text { totalmente }\end{array}$ & 2 & 3 & 4 & & $\begin{array}{l}6 \\
\text { concordo } \\
\text { totalmente }\end{array}$ \\
\hline
\end{tabular}


Quadro 2. continuação

\begin{tabular}{|c|c|c|c|c|c|c|}
\hline 28. Meu trabalho faz mal para minha saúde. & $\begin{array}{c}0 \quad 1 \\
\text { discordo } \\
\text { totalmente }\end{array}$ & 2 & 3 & 4 & 5 & $\begin{array}{l}6 \\
\text { concordo } \\
\text { totalmente }\end{array}$ \\
\hline $\begin{array}{l}\text { 29. Quando estou de licença-saúde, eu me sinto mal por } \\
\text { ficar tão atrasado com meu trabalho. }\end{array}$ & $\begin{array}{c}0 \quad 1 \\
\text { discordo } \\
\text { totalmente }\end{array}$ & 2 & 3 & 4 & 5 & $\begin{array}{l}6 \\
\text { concordo } \\
\text { totalmente }\end{array}$ \\
\hline 30. Eu me sinto entediado (aborrecido) com meu trabalho. & $\begin{array}{c}0 \quad 1 \\
\text { discordo } \\
\text { totalmente }\end{array}$ & 2 & 3 & 4 & 5 & $\begin{array}{l}6 \\
\text { concordo } \\
\text { totalmente }\end{array}$ \\
\hline $\begin{array}{l}\text { 31. Eu tenho um bom relacionamento com meus colegas de } \\
\text { trabalho. }\end{array}$ & $\begin{array}{c}0 \quad 1 \\
\text { discordo } \\
\text { totalmente }\end{array}$ & 2 & 3 & 4 & 5 & $\begin{array}{l}6 \\
\text { concordo } \\
\text { totalmente }\end{array}$ \\
\hline $\begin{array}{l}\text { 32. Quando eu estou sentindo dor, meus familiares e } \\
\text { amigos procuram fazer alguma coisa para eu me esquecer } \\
\text { da minha dor. }\end{array}$ & $\begin{array}{c}0 \quad 1 \\
\text { discordo } \\
\text { totalmente }\end{array}$ & 2 & 3 & 4 & 5 & $\begin{array}{l}6 \\
\text { concordo } \\
\text { totalmente }\end{array}$ \\
\hline $\begin{array}{l}\text { 33. Eu nunca teria sentido nenhuma dor se eu tivesse tido } \\
\text { outro tipo de trabalho }\end{array}$ & $\begin{array}{c}0 \quad 1 \\
\text { discordo } \\
\text { totalmente }\end{array}$ & 2 & 3 & 4 & 5 & $\begin{array}{l}6 \\
\text { concordo } \\
\text { totalmente }\end{array}$ \\
\hline $\begin{array}{l}\text { 34. Durante meu dia de trabalho, existem muitas operações } \\
\text { de trabalho pesado. }\end{array}$ & $\begin{array}{c}0 \\
\text { discordo } \\
\text { totalmente }\end{array}$ & 2 & 3 & 4 & 5 & $\begin{array}{l}6 \\
\text { concordo } \\
\text { totalmente }\end{array}$ \\
\hline $\begin{array}{l}\text { 35.A desvantagem de trabalhar é que eu não tenho tempo } \\
\text { para outras coisas. }\end{array}$ & \begin{tabular}{|c}
0 \\
discordo \\
totalmente
\end{tabular} & 2 & 3 & 4 & 5 & $\begin{array}{l}6 \\
\text { concordo } \\
\text { totalmente }\end{array}$ \\
\hline 36. Eu acho meu horário de trabalho insatisfatório. & $\begin{array}{c}0 \quad 1 \\
\text { discordo } \\
\text { totalmente }\end{array}$ & 2 & 3 & 4 & 5 & $\begin{array}{l}6 \\
\text { concordo } \\
\text { totalmente }\end{array}$ \\
\hline $\begin{array}{l}\text { 37. Quando eu retorno ao trabalho, eu preciso trabalhar } \\
\text { muito para compensar tudo o que perdi durante minha } \\
\text { licença-saúde. }\end{array}$ & $\begin{array}{c}0 \quad 1 \\
\text { discordo } \\
\text { totalmente }\end{array}$ & 2 & 3 & 4 & 5 & $\begin{array}{l}6 \\
\text { concordo } \\
\text { totalmente }\end{array}$ \\
\hline $\begin{array}{l}\text { 38. Quando eu estou com dor, meus familiares e amigos } \\
\text { não suportam ficar perto de mim. }\end{array}$ & $\begin{array}{c}0 \quad 1 \\
\text { discordo } \\
\text { totalmente }\end{array}$ & 2 & 3 & 4 & 5 & $\begin{array}{l}6 \\
\text { concordo } \\
\text { totalmente }\end{array}$ \\
\hline $\begin{array}{l}\text { 39. Quando eu trabalho, tenho muito pouco tempo para } \\
\text { meus familiares e amigos. }\end{array}$ & $\begin{array}{c}0 \\
\text { discordo } \\
\text { totalmente }\end{array}$ & 2 & 3 & 4 & 5 & $\begin{array}{l}6 \\
\text { concordo } \\
\text { totalmente }\end{array}$ \\
\hline $\begin{array}{l}\text { 40. É ruim o fato dos meus colegas de trabalho não } \\
\text { compreenderem minha dor. }\end{array}$ & $\begin{array}{c}0 \\
\text { discordo } \\
\text { totalmente }\end{array}$ & 2 & 3 & 4 & 5 & $\begin{array}{l}6 \\
\text { concordo } \\
\text { totalmente }\end{array}$ \\
\hline $\begin{array}{l}\text { 41. Eu preciso ficar em casa por causa dos meus problemas } \\
\text { familiares. }\end{array}$ & $\begin{array}{c}0 \\
0 \\
\text { discordo } \\
\text { totalmente }\end{array}$ & 2 & 3 & 4 & 5 & $\begin{array}{l}6 \\
\text { concordo } \\
\text { totalmente }\end{array}$ \\
\hline
\end{tabular}

continua

tra em que foram testadas ${ }^{43-45}$, o ORTWQ, assim como qualquer outro instrumento não pode por si só ser considerado válido e confiável para uma população em geral. Sendo assim, esse questionário ainda precisa ser verificado quanto à qualidade das suas propriedades psicométricas.

Mesmo em sua versão original, pesquisadores indicam que há uma possibilidade dos resultados do ORTWQ estarem superestimados devido à presença de um grande número de itens em alguns domínios e devido à análise fatorial descrita ter sido testada em uma amostra de apenas 121 indivíduos ${ }^{18}$.

Além disso, estudo ${ }^{18}$ salienta a importância de que outras pesquisas se atentem para desenvolver mais profundamente o ORTWQ bem 
Quadro 2. continuação

\begin{tabular}{|c|c|c|c|c|c|c|}
\hline \multicolumn{7}{|c|}{$\begin{array}{l}\text { Seção III: Aqui estão algumas questões sobre como você considera as suas possibilidades de retornar ao } \\
\text { trabalho. Por favor, circule uma alternativa em cada questão. }\end{array}$} \\
\hline $\begin{array}{l}\text { 1. Na sua opinião, qual a chance que existe de você } \\
\text { conseguir retornar ao trabalho? }\end{array}$ & $\begin{array}{c}0 \\
\text { nenhuma } \\
\text { chance }\end{array}$ & 2 & 3 & 4 & & $\begin{array}{l}6 \\
\text { uma grande } \\
\text { chance }\end{array}$ \\
\hline 2. Como você acha que será o seu retorno ao trabalho? & $\begin{array}{cc}0 & 1 \\
\text { nada } & \\
\text { difícil } & \\
\end{array}$ & 2 & 3 & 4 & 5 & $\begin{array}{l}6 \\
\text { muito } \\
\text { difícil }\end{array}$ \\
\hline $\begin{array}{l}\text { 3. O quanto convencido você está de que você vai se } \\
\text { recuperar? }\end{array}$ & $\begin{array}{c}0 \\
\text { nada } \\
\text { convencido }\end{array}$ & 2 & 3 & 4 & 5 & $\begin{array}{l}6 \\
\text { totalmente } \\
\text { convencido }\end{array}$ \\
\hline $\begin{array}{l}\text { 4. Quanta chance você acha que existe de você ser capaz de } \\
\text { retornar ao trabalho nos próximos seis meses? }\end{array}$ & $\begin{array}{c}01 \\
\text { nenhuma } \\
\text { chance }\end{array}$ & 2 & 3 & 4 & 5 & $\begin{array}{l}6 \\
\text { uma grande } \\
\text { chance }\end{array}$ \\
\hline $\begin{array}{l}\text { 5. Como você se sente quando pensa sobre as suas } \\
\text { possibilidades de retornar ao trabalho? }\end{array}$ & $\begin{array}{cc}0 & 1 \\
\text { nada } \\
\text { otimista }\end{array}$ & 2 & 3 & 4 & 5 & $\begin{array}{l}6 \\
\text { muito } \\
\text { otimista } \\
\end{array}$ \\
\hline $\begin{array}{l}\text { 6. Como você se sente quando pensa sobre as suas } \\
\text { possibilidades de viver sem assistência médica no futuro? }\end{array}$ & $\begin{array}{cc}0 & 1 \\
\text { nada } \\
\text { otimista }\end{array}$ & 2 & 3 & 4 & 5 & $\begin{array}{l}6 \\
\text { muito } \\
\text { otimista } \\
\end{array}$ \\
\hline
\end{tabular}

como a melhorá-lo. As sugestões se dão no sentido de incluir outros tipos de população, aumentar o tamanho da amostra, avaliar sua capacidade preditiva quanto ao retorno ao trabalho e quanto à manutenção desse retorno ao trabalho, reduzir o número de domínios e desenvolver uma série de pontos de corte a fim de auxiliar a tomada de decisão clínica e associá-las com intervenções de tratamento.

Sendo assim, disponibilizar o ORTWQ traduzido para o português e adaptado à cultura brasileira permitirá outros pesquisadores e/ou profissionais de saúde a testarem as qualidades psicométricas desse questionário também em outros grupos de trabalhadores brasileiros com objetivo de melhorá-lo e adequá-lo conforme as características específicas de cada amostra. Estes grupos de trabalhadores podem ser pertencentes a uma função/ocupação específica e/ou acometidos por outros agravos diferentes dos distúrbios osteomusculares.

No Brasil poucos são os estudos relacionados à temática "retorno ao trabalho" e não foi encontrado nenhum estudo que propusesse um instrumento para identificar os fatores relacionados aos obstáculos de retorno ao trabalho de trabalhadores que estão ou estiveram afastados. Considerado um país em desenvolvimento, o Brasil começa a enfrentar questões relativas ao envelhecimento populacional $1^{9,11}$ e é preocupan- te o fato de que poucas estratégias estejam sendo adotadas para lidar com essa situação, bem como para lidar com questão dos trabalhadores doentes e afastados do trabalho.

No sentido de que sejam atribuídos recursos necessários àqueles pacientes que mais necessitam, é importante que profissionais de saúde envolvidos na reabilitação sejam capazes de avaliar esses pacientes com relação às suas chances de retorno à vida laboral ${ }^{20}$.

$\mathrm{Na}$ perspectiva dos pacientes/trabalhadores, a identificação e avaliação dos obstáculos para o retorno ao trabalho são importantes de modo que estes possam aprender estratégias de enfrentamento e possam se adaptar novamente à vida de trabalho ${ }^{20,46}$.

A existência de um instrumento/questionário que identifique essas dificuldades poderá fornecer informações importantes no sentido de orientar a tomada de decisões dos profissionais de saúde. Essas informações podem auxiliar no planejamento e seleção de intervenções apropriadas e tratamentos para o paciente durante um programa de reabilitação e consequentemente reduzir os longos períodos de incapacidade para o trabalho e de afastamento por doença ${ }^{12,24}$. Dentre as diversas possibilidades de uso do ORTWQ, ele pode, por exemplo, ser empregado em pacientes/ trabalhadores que visitam ou que procuram um centro de reabilitação profissional para sua 
primeira consulta. A partir das respostas ao questionário, os principais obstáculos para retorno ao trabalho são identificados, e consequentemente as condutas dos profissionais de saúde, estarão mais direcionadas ao que é mais importante para aquele determinado paciente.

Uma vez que o ORTWQ tem sido mencionado na literatura como uma ferramenta de resultados promissores, a disponibilidade da sua versão brasileira possibilitará que seja testado quanto a essa potencialidade, além de permitir a comparação dos resultados brasileiros com diferentes contextos.

Dentre algumas limitações quanto ao uso do ORTWQ, cita-se o tamanho do questionário, que em um primeiro momento pode ser visto como longo (55 itens). O questionário ainda precisa de uma maior investigação quanto a sua validade preditiva e quanto às suas qualidades psicométricas e algumas das suas subescalas também necessitam de maior investigação, como, por exemplo, a "preocupação devido ao afastamento".

De forma mais ampla, o ORTWQ pode contribuir para a capacidade de coleta e análise de dados, para uma produção sistematizada de informações para intervenções e para tomada de posições que ultrapassem a dimensão assistencial. O uso e a aplicação do ORTWQ podem ser integrados também a ações de educação e promoção da saúde do trabalhador, redução da morbimortalidade decorrentes dos processos laborais, na autopercepção e participação dos trabalhadores em sua compreensão mais ampliada sobre a relação saúde e trabalho. Defendemos que por menor que seja uma ação, esta pode for- talecer a Renast e, consequentemente, realizar ações efetivas de atenção integral e transversal de Vigilância à saúde do trabalhador.

\section{Conclusão}

O presente estudo discutiu a importância do tema e da avaliação de fatores relacionados ao retorno ao trabalho, dor e distúrbios osteomusculares, para o complexo campo da saúde do trabalhador. O estudo disponibilizou também a versão traduzida e adaptada culturalmente do Obstacles to Return-to-Work Questionnaire para o contexto brasileiro. $\mathrm{O}$ instrumento demonstrou equivalências: conceitual, semântica e idiomática satisfatórias entre a versão original e a traduzida, sendo necessárias algumas alterações para que o instrumento se adequasse ao contexto brasileiro. Sendo um dos raros questionários que aborda retorno ao trabalho no Brasil, esse instrumento poderá ter relevante aplicação no sentido de planejar intervenções apropriadas para reduzir a incapacidade para o trabalho, promover retorno ao trabalho e contribuir para a Vigilância em Saúde do Trabalhador. Estudos ainda são necessários para analisar a qualidade das propriedades psicométricas do ORTWQ. A disponibilidade de um instrumento traduzido e adaptado culturalmente permite que outros pesquisadores e/ou profissionais de saúde interessados na temática do retorno ao trabalho também possam testá-lo e avaliar suas qualidades, bem como ajustá-lo e adequá-lo para trabalhadores brasileiros em ocupações específicas e/ou acometidos por agravos diferentes dos distúrbios osteomusculares.

\section{Colaboradores}

D Milani e NMC Alexandre trabalharam na elaboração do projeto, coleta e interpretação dos dados, redação e revisão crítica do artigo. MS Hirayama e AC Souza trabalharam na interpretação dos dados, redação e revisão crítica do artigo.

\section{Agradecimentos}

A todos os especialistas que contribuíram na revisão do questionário adaptado.

À Coordenação de Aperfeiçoamento de Pessoal de Nível Superior (CAPES-Brasil) e ao Conselho Nacional de Desenvolvimento Científico e Tecnológico (CNPq-Brasil). 


\section{Referências}

1. Brasil. Ministério da Saúde (MS). Conselho Nacional de Saúde. Relatório Final da $4^{a}$ Conferência Nacional de Saúde do Trabalhador e da Trabalhadora. Brasília: MS; 2015. [acessado 2016 Jan 20]. Disponível em: http://renastonline.ensp.fiocruz.br/sites/default/files/arquivos/ recursos/Relatorio_4cnstt_final_31072015.pdf

2. Brasil. Lei no 8.080, de 19 de setembro de 1990. Dispõe sobre as condições para a promoção, proteção e recuperação da saúde, a organização e o funcionamento dos serviços correspondentes e dá outras providências. $D i$ ário Oficial da União 1990; 20 set.

3. Costa D, Lacaz FAC, Jackson Filho JM, Vilela RAG. Saúde do Trabalhador no SUS: desafios para uma política pública. Rev. bras. saúde ocup. 2013; 38(127):11-30.

4. Brasil. Decreto $n^{\circ} 7.602$, de 7 de novembro de 2011. Dispõe sobre a Política Nacional de Segurança e Saúde no Trabalho - PNSST. Diário Oficial da União 2011; 8 nov.

5. Brasil. Portaria $n^{\circ} 1.823$, de 23 de agosto de 2012. Institui a Política Nacional de Saúde do Trabalhador e da Trabalhadora. Diário Oficial da União 2012; 24 ago.

6. Leão LHC, Vasconcellos LCF. Rede nacional e atenção integral à saúde do trabalhador (Renast):uma rede que não enreda. In: Vasconcellos LCF, Oliveira MHB, organizadores. Saúde, trabalho e direito: uma trajetória crítica e a crítica de uma trajetória. Rio de Janeiro: Educam; 2011. p. 453-489.

7. Minayo-Gomes C. Avanços e entraves na implementação da Política Nacional de Saúde do Trabalhador. Rev. bras. Saúde ocup. 2013; 38(127):11-30.

8. Punnett L, Wegman L. Work-related musculoskeletal disorders: the epidemiologic evidence and the debate. J Electromyogr Kinesiol 2004; 14(1):13-23.

9. Monteiro MS, Alexandre NMC, Rodrigues CM. Doenças musculoesqueléticas, trabalho e estilo de vida entre trabalhadores de uma instituição pública de saúde. Rev Esc Enferm 2006; 40(1):20-25.

10. Walsh IAP, Corral S, Franco RN, Canetti EEF, Além MER, Coury HJCG. Capacidade para o trabalho em indivíduos com lesões musculoesqueléticas crônicas. Rev Saude Publica 2004; 38(2):149-156.

11. Monteiro MS. Alexandre NM, Ilmarinen J, Rodrigues CM. Work ability and musculoskeletal disorders among workers from a Public Health Institution. Int $J$ Occup Saf Ergonom (JOSE) 2009; 15(3):319-324.

12. Loisel P, Buchbinder R, Hazard R, Keller R, Scheel I, van Tulder M, Webster B. Prevention of work disability due to musculoskeletal disorders: the challenge of implementing evidence. J Occup Rehabil 2005; 15(4):507524.

13. Coutu MF, Durand MJ, Loisel P, Dupuis G, Gervais S. Measurement properties of a new quality of life measure for patients with work disability associated with musculoskeletal pain. J Occup Rehabil 2005; 15(3):295312.
14. Brasil. Ministério da Previdência Social. Anuário estatístico da Previdência Social. Brasília: Ministério da Previdência Social; 2013. [acessado 2016 Jan 20 ]. Disponível em: http://www.previdencia.gov.br/wp-content/ uploads/2013/05/AEPS_2012.pdf

15. Brasil. Ministério da Previdência Social. Acompanhamento Mensal dos Benefícios Auxílios-Doença Previdenciários Concedidos segundo os códigos CID-10 - Janeiro a Dezembro de 2013. Brasília: Ministério da Previdência Social; 2014. [acessado 2016 Jan 20 ]. Disponível em: http://www.previdencia.gov.br/wp-content/uploads/2013/05/Aux-Doenca-Conc-Prev-e-Acid-X-CID-eClientela_2013_separado-ate-DEZ-previdenciarios.pdf

16. Brasil. Ministério da Previdência Social. Acompanhamento Mensal dos Benefícios Auxílios-Doença Acidentários Concedidos, segundo os códigos CID-10 - Janeiro a Dezembro de 2013. Brasília: Ministério da Previdência Social; 2014. [acessado 2016 Jan 20 ]. Disponível em: http://www.previdencia.gov.br/wp-content/uploads/2013/05/Aux-Doenca-Conc-Prev-e-Acid-X-CID-e-Clientela_2013_separado-ate-DEZ-acidentarios. pdf

17. Maciel ACC, Fernandes MB, Medeiros MLS. Prevalência e fatores associados à sintomatologia dolorosa entre profissionais da indústria têxtil. Rev Bras Epidemiol 2006; 9(1):94-102.

18. Gray H, Adefolarin AT, Howe TE. A systematic review of instruments for the assessment of work-related psychosocial factors (Blue Flags) in individuals with non-specific low back Pain. Man Ther 2011; 16(6):531543.

19. Bongers PM, deWinter CR, Kompier MAJ, Hildebrandt VH. Psychosocial factors at work and musculoskeletal disease. Scand J Work Environ Health 1993; 19(5):297312.

20. Marhold C, Linton SJ, Melin L, Identification of obstacles for chronic pain patients to return to work: Evaluation of a questionnaire. J. Occup. Rehabil. 2002; 12(2):65-75.

21. Iles RA, Davidson M, Taylor NF. Psychosocial predictors of failure to return to work in non-chronic non-specific low back pain: a systematic review. Occup Environ Med 2008; 65(8):507-517.

22. Heitz CAM, Hilfiker R, Bachmann LM, Joronen H, Lorenz T, Uebelhart D, Klipstein A, Brunner F. Comparison of risk factors predicting return to work between patients with subacute and chronic non-specific low back pain: systematic review. Eur Spine J 2009; 18(12):1829-1835.

23. Chou R, Shekelle P. Will this patient develop persistent disabling low back pain? J Am Med Assoc 2010; 303(13):1295-1302.

24. Pransky G, Gatchel R, Linton SJ, Loisel P. Improving return to work research. J Occup Rehabil 2005; 15(4):453457. 
25. Waddell G, Aylward M, Sawney P. Back pain, incapacity for work and social security benefits: An international literature review and analyses. London: The Royal Society of Medicine Press; 2002.

26. Sullivan MJL, Feuerstein M, Gatchel R, Linton SJ, Pransky G. Integrating Psychosocial and behavioral interventions to achieve optimal rehabilitation outcomes. J Occup Rehabil 2005; 15(4):475-489.

27. Blyth FM, March LM, Broabic AJM, Cousins MJ. Chronic pain, work performance and frequent use of health care. Pain 2004; 111(1-2):51-58.

28. Grimmer-Somers K, Vipond N, Kumar S, Hall G. A review and critique of assessment instruments for patients with persistent Pain J Pain Res. 2009; 2(1):21-47.

29. Blyth FM, March LM, Nicholas M, Cousins MJ. Chronic pain, work performance and litigation. Pain 2003; 103(1-2):41-47.

30. Hagen EM, Eriksen HR, Ursin H. Does early intervention with a light mobilization program reduce long-term sick leave for low back pain? Spine 2000; 25(15):1973-1976.

31. Gatchell RJ, Polatin PB, Noe C, Gardea M, Pulliam C, Thompson J. Treatment-and cost-effectiveness of early intervention for acute low-back pain patients: a oneyear prospective study. J Occup Rehabil 2003; 13(1):1-9.

32. Wand BM, Bird C, Mc Auley JH, Dóre CJ, Mac Dowell M, De Souza LH. Early intervention for the management of acute low back pain: a single-blind randomized controlled trial of biopsychosocial education, manual therapy and exercise. Spine 2004; 29(21):2350-2356.

33. Linton SJ, Boersma K. Early identification of patients at risk of developing a persistent back problem: the predictive validity of the Orebro Musculosketal pain questionnaire. Clin J Pain 2003; 19(2):80-86.

34. Gatchel RJ. Musculoskeletal disorders: Primary and secondary intervention. J Electromyor Kinesiol 2004; 14:161-170.

35. Vasconcelos LCF, Minayo-Gomes C, Machado JMH. Entre o definido e o por fazer na Vigilância em Saúde do Trabalhador. Cien Saude Colet 2014; 19(12):46174626.

36. Marois E, Durand MJ. Does participation in interdisciplinary work rehabilitation programme influence return to work obstacles and predictive factors? Disabil Rehabil 2009; 31(12):994-1007.

37. Beaton D, Bombardier C, Guillemin F, Ferraz MB. Recommendations for the cross-cultural adaptation of the DASH \& Quick DASH outcome measures. [Internet]. Toronto: Institute for Work \& Health; 2007. p. 1-45. [acessado 2016 Jan 20 ]. Disponível em: http://dash. iwh.on.ca/system/files/X-CulturalAdaptation-2007. pdf.

38. Alexandre NMC, Guirardello EB. Adaptación cultural de instrumentos utilizados en salud ocupacional. Rev Panam Salud Publica 2002; 11(2):109-111.
39. Alexandre NMC, Coluci MZO. Validade de conteúdo nos processos de construção e adaptação de instrumentos de medida. Cien Saude Colet 2011; 16(7):30613067.

40. Grimmer-Somers K, Kumar S, Vipond N, Hall G. Primary care assessment instruments for patients at risk of, or with, persistent pain: opportunistic findings from a systematic literature review. Int J Gen Med 2009; 2:121-128.

41. Kausto J, Miranda H, Martimo K, Viikari-Juntura E. Partial sick leave - review of its use, effects and feasibility in the Nordic countries. Scand $j$ work environ. health $2008 ; 34(4): 239-249$.

42. Viikari-Juntura E, Kausto J, Shiri R, Kaila-Kangas L, Takala EP, Karppinen J, Miranda H, Luukkonen R, Martimo KP. Return to work after early part-time sick leave due to musculoskeletal disorders: a randomized controlled trial. Scand j work environ. health 2012; 38(2):134-143.

43. Streiner DL, Norman GR, Cairney J. Health measurements scales. A pratical guide to their development and use. $5^{\text {th }}$ ed. New York: Oxford University Press; 2015.

44. Pais-Ribeiro JL. Medida na avaliação psicologica. Psicol. Saude doencas 2013; 14(1):245-263.

45. Maroco J. Analise de equações estruturais. Lisboa: Report Number; 2010.

46. Marhold C, Linton SJ, Melin L. A cognitive-behavioral return-to-work program: Effects on pain patients with a history of long-term versus short-term sick leave. Pain 2001; 91(1-2):155-163.

Artigo apresentado em 03/10/2014

Aprovado em 25/07/2016

Versão final apresentada em 27/07/2016 